\title{
Considerations and a call to action for the use of noncontact forehead infrared handheld thermometers during the COVID-19 pandemic
}

\section{Wing P Chan ${ }^{1,2}$, Russell Oliver Kosik², C Jason Wang ${ }^{3,4}$}

${ }^{1}$ Department of Radiology, Wan Fang Hospital, Taipei Medical University, Taipei, Taiwan

${ }^{2}$ Department of Radiology, School of Medicine, College of Medicine, Taipei Medical University, Taipei, Taiwan

${ }^{3}$ Departments of Pediatrics, Medicine, and Health Research and Policy, Stanford University School of Medicine, Stanford, California, USA

${ }^{4}$ The New School for Leadership in Health Care, Koo Foundation Sun Yat-Sen Cancer Center, Taipei, Taiwan

$\mathrm{E}$ arly in January 2020, the WHO announced that temperature screening at entry was sufficient to detect the majority of imported COVID-19 cases [1]. As such, several countries began employing thermal screening in airports and public places as a preventative measure against the spread of coronavirus. A February 20th report from the WHO noted that among 55924 laboratory confirmed cases of COVID-19 in China, 87.9\% had a "fever" (no cutoff point reported), and people with COVID-19 generally developed signs (including fever) and symptoms on average 5-6 days following exposure (range 1-14 days or even longer). However, there is a lack of a universally

Human body temperatures and their measurements can vary quite significantly, which limits the sensitivity of temperature screening. accepted definition of what exactly constitutes "fever" when a noncontact infrared thermometer is used.

Prior research has shown that a forehead temperature in excess of 35.6 [2], or $36.2^{\circ} \mathrm{C}$ if measured indoors [3], is suggestive of fever. The definition of fever remains unclear however, as body temperature is influenced by many factors including site and time of measurement, one's environment (indoors vs outdoors), activities performed prior to measurement, age, ovulatory cycle, type of thermometer used, and expected variations between and within individuals. For example, older adults' (age $\geq 60$ ) temperatures are $0.23^{\circ} \mathrm{C}$ lower than younger adults (age $<60$ ) on average [4]. Most authors [5,6] agree that the mean normal oral temperature is $36.8 \pm 0.4^{\circ} \mathrm{C}\left(98.2^{\circ} \mathrm{F}\right)$. If this threshold is breached (early morning: $>37.2^{\circ} \mathrm{C}$ or $>99^{\circ} \mathrm{F}$; any other time during the day: $37.7^{\circ} \mathrm{C}$ or $>100^{\circ} \mathrm{F}$ ), which is roughly equivalent to a rectal temperature of $\geq 38^{\circ} \mathrm{C}$ $\left(100.4^{\circ} \mathrm{F}\right)$ and an axillary temperature of $\geq 37.5^{\circ} \mathrm{C}\left(99.5^{\circ} \mathrm{F}\right)$, a fever is present as defined by the WHO [7]. Of the three major measuring sites (ie, rectal, oral, and axillary), rectal temperatures most accurately estimate core temperature [6]. Yet, there are no guidelines to allow for comparison of body temperatures across different body sites, including the forehead.

Additionally, even though handheld noncontact infrared thermometers are convenient and safe, they are operator dependent and offer low sensitivity (29.4\%) compared to oral temperature measurements [8]. Some manufacturers have suggested an optimum measurement distance of 2 to 6 inches or 5 to $15 \mathrm{~cm}$ when placed perpendicular to the forehead. Ng et al. [2] measured the forehead temperatures of 1000 healthy individuals using handheld infrared thermometers and determined that $35.6^{\circ} \mathrm{C}$ should serve as a cutoff measurement 


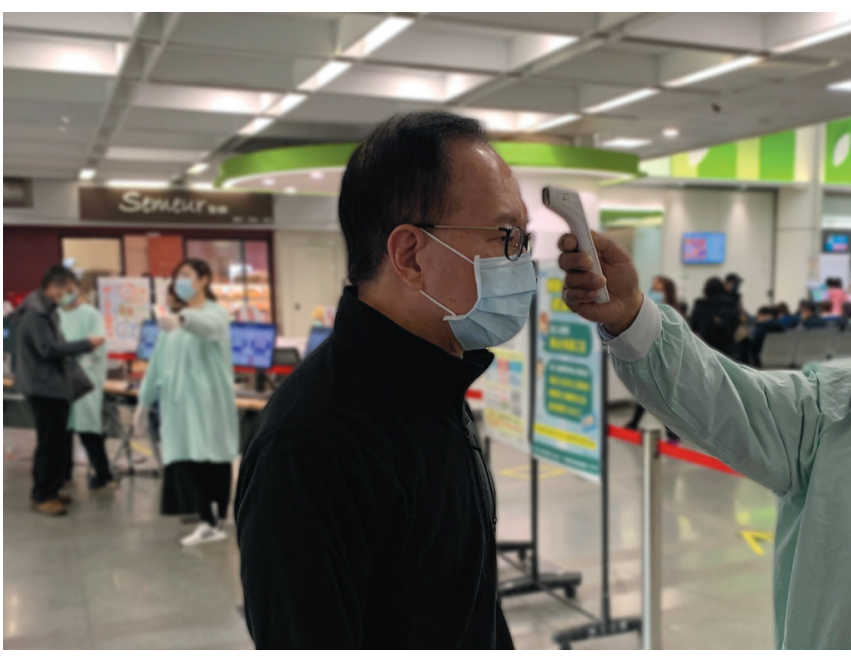

Photo: Temperature screening at the hospital entrance (image by Wing Chan, used with permission). between healthy and febrile individuals. Chen et al. [3] recorded the tympanic temperatures of 528 (261 indoor and 267 outdoor) participants to be used as a standard for forehead infrared measurements. When a tympanic temperature of $37.3^{\circ} \mathrm{C}$ or above was considered febrile, a corresponding cut-off value of $36.2^{\circ} \mathrm{C}$ when using a contact infrared thermometer at the wrist was determined ( $86.4 \%$ sensitivity and $67.0 \%$ specificity). Similarly, this corresponded to a cutoff value of $36.2^{\circ} \mathrm{C}$ when measured at the forehead indoors (93.2\% sensitivity and $60.0 \%$ specificity) [3]. This work implies that reference ranges for fever measured with infrared technology can vary substantially by body site.

Ideally, equivocal temperatures identified during screening in public places using handheld infrared thermometers should be rechecked with a tympanic thermometer or an oral thermometer. Further, adequate reference information for infrared screening would reduce the rate of false negatives.

Forehead measurements with infrared technology offer the convenience of contactless mass screening and do not require subjects to remove their clothes. However, validation of the accuracy and precision of this technology across different instruments, body sites, and environments is urgently needed. Moreover, the threshold for fever using infrared technology may be lower than those used

The pandemic offers a unique opportunity to gather widespread temperature data that may increase the sensitivity of screening. for tympanic and oral measurements. In cities all over the world, tens of thousands of temperature measurements are performed daily. If just a fraction of this data were recorded and made available to investigators, it would provide invaluable information concerning the range of normal body temperature. Further, because many people are measured multiple times per day and in different settings, such data could offer insights into how temperatures vary over time and across settings. This data would allow those in the public health space to select more appropriate cutoff temperatures in screening for potential COVID-19 infections. While collecting and organizing such data would certainly require some effort, the pandemic offers a unique opportunity to do so, and it should not be wasted.

\section{Funding: We received no funding for this study.}

Authorship contributions: W.P. Chan wrote the first draft. All of the authors reviewed manuscript drafts, provided intelligent inputs, and approved the final version.

Conflict of interest statement: The authors completed the ICMJE Unified Competing Interest form (available upon request from the corresponding author), and declare no further conflicts of interest.

1 World Health Organization. Available: https://www.who.int/ith/2020-24-01-outbreak-of-Pneumonia-caused-by-new-coronavirus/en/. Accessed: 30 August 2020.

$2 \mathrm{Ng}$ DK, Chan CH, Chan EY, Kwok KL, Chow PY, Lau WF, et al. A brief report on the normal range of forehead temperature as determined by noncontact, handheld, infrared thermometer. Am J Infect Control. 2005;33:227-9. Medline:15877017 doi:10.1016/j.ajic.2005.01.003

3 Chen G, Xie J, Dai G, Zheng P, Hu X, Lu H, et al. Validity of wrist and forehead temperature in temperature screening in the general population during the outbreak of 2019 novel coronavirus: a prospective real-world study. medRxiv preprint. Available: https://www.medrxiv.org/content/10.1101/2020.03.02.20030148v1. Accessed: 30 August 2020.

4 Mackowiak PA. Temperature regulation and pathogenesis of fever. Mandell, Douglas and Bennett's Principles and practice of infectious disease. London: Elsevier Churchill Livingstone; 2005.

5 Dinarello CA, Gelfand JA. Fever and hyperthermia. In: Fauci AS, Kasper DL, Longo DL, Braunwald E, Hauser SL, Jameson JL, Loscalzo J, editors. Harrison's principles of internal medicine. London: McGraw-Hill's Co; 2005.

6 Ogoina D. Fever, fever patterns and diseases called 'fever' — a review. J Infect Public Health. 2011;4:108-24. Medline:21843857 doi:10.1016/j.jiph.2011.05.002 
7 WHO guidelines for the global surveillance of severe acute respiratory syndrome (SARS). Updated recommendations, October 2004. Avaiable: https://www.who.int/csr/resources/publications/WHO_CDS_CSR_ARO_2004_1.pdf?ua=1. Accessed: 30 August 2020.

$8 \mathrm{Aw}$ J. The non-contact handheld cutaneous infra-red thermometer for fever screening during the COVID-19 global emergency. J Hosp Infect. 2020;104:451. Medline:32092368 doi:10.1016/j.jhin.2020.02.010

\section{Correspondence to:}

Wing P. Chan, MD

Department of Radiology

Wan Fang Hospital

Taipei Medical University

111 Hsing Long Road

Section 3, Taipei 116

Taiwan

wingchan@tmu.edu.tw 